\title{
1 Variations in sub-daily precipitation at centennial scale
}

2

3

4

5

6

7

8

Kristian Förster*, Luisa-Bianca Thiele

foerster@iww.uni-hannover.de, thiele@iww.uni-hannover.de, Institute of Hydrology and Water Resources Management, Leibniz Universität Hannover, Appelstr. 9A, D-30167 Hannover, Germany, Tel.: +49 511 762-2498 / Fax: 3731, http://www.iww.uni-hannover.de/

\section{This paper is a non-peer reviewed preprint submitted to EarthArXiv.}

Short-term precipitation events with high intensities govern the dynamics of numerous fast hydrological processes like flash floods ${ }^{1}$ in urban areas and soil erosion ${ }^{2}$ in agriculture. It is expected that precipitation events will intensify as a consequence of climate change ${ }^{3-8}$. Due to data availability long-term variations in precipitation rates are mostly studied based on daily precipitation recordings ${ }^{9-}$

12 while recent research suggests that variations in sub-daily precipitation are subject to higher dynamics compared to daily precipitation and a more rapid intensification is likely ${ }^{4,13}$. Here we show that both observational data with at least 58 years of sub-daily precipitation records and a minimal dynamical downscaling approach based on atmospheric re-analysis data confirm these expectations with consistent results. High quantiles of precipitation are subjected to multi-decadal oscillations and increased during the last 150 years. For the 2000 s we found positive anomalies in high precipitation quantiles relative to the reference period $1850-2014$ of $6 \% \pm 5 \%$ (daily), $13 \pm 6 \%$ (hourly), and $14 \% \pm$ 6\% (10 min), which is consistent with Clausius-Clapeyron- (CC) and super CC-scaling, respectively. 
These findings highlight that dynamical downscaling can help to reliably shed light on sub-daily precipitation variations if small timescales are considered in the experiments.

Recent studies focused on unravelling the relationship between temperature and precipitation which follows the Clausius-Clapeyron (CC) equation suggesting that precipitation extremes - or more specifically the saturation vapor pressure - increase by $7 \%$ per degree of warming ${ }^{9,14}$ or even exceeding this rate (super CC-scaling) $)^{3,4,14,15}$. Trend analyses involving long-term records of precipitation extremes are mostly in agreement with these findings in view of the fact that two thirds of stations worldwide showed increasing trends ${ }^{12}$. Other studies found more stations with negative than positive trends in summer precipitation extremes in Europe ${ }^{10}$. Moreover, since temperature-precipitation-scaling also shows decreasing rates above a certain temperature or dewpoint level, it is argued that these scaling approaches are not valid under all possible conditions and thus they are not suitable for projecting changes in precipitation extremes ${ }^{16}$.

Global Circulation Models (GCMs) and Regional Climate Models (RCMs) are capable of representing changes in precipitation characteristics at longer time scales (e.g., seasonal) ${ }^{4}$. Their applicability to reconstruct changes in sub-daily precipitation is viewed uncertain due to (i) missing validation data at sub-daily time scales with sufficient record length and the (ii) uncertainties involved in convection parametrizations which are needed for grid spacings larger than $5 \mathrm{~km}^{4,8}$. Recent convection-resolving RCMs with higher spatial resolution below $5 \mathrm{~km}$ do not need such parameterizations and thus are viewed promising for simulating sub-daily rainfall ${ }^{4,6,8}$ even though they are still subjected to uncertainties ${ }^{4,16}$. However, coarser scale GCM and RCM simulations are still capable to represent relevant characteristics of sub-daily precipitation extremes ${ }^{14,17,18}$. They also reproduce temporal changes and trends on decadal scales ${ }^{19}$. For climate projections on the global scale convection parameterizations are still relevant since convection-permitting models are demanding in terms of computational resources ${ }^{4,16}$. 
Even though the availability of long-term records of sub-daily precipitation is very limited, these findings highlight the relevance of validating RCMs and GCMs in terms of their ability to predict subdaily precipitation and its sensitivity to climate variability and more specifically climate change. Climate variability including both natural climate variability and anthropogenic forcing affect changes in precipitation extremes over time ${ }^{13}$, whereby natural climate variability can mask the anthropogenic signal caused by greenhouse gas emissions ${ }^{20}$. While long-term records of daily precipitation are in general more readily available ${ }^{1,21}$ and reflect higher evidence ${ }^{9-12}$, only a few studies focus on sub-daily precipitation ${ }^{8,13,22}$. Transferring results from analyses involving daily precipitation to smaller temporal scales is not reliable due to the higher temperature sensitivity of precipitation processes relevant at time scales below one day ${ }^{4}$.

In this study, we address the impediment to validate sub-daily precipitation simulations under nonstationary conditions imposed by climate variability and climate change through compiling long-term records of sub-hourly precipitation to provide a comprehensive dataset for model validation. We analyse a set of sub-daily precipitation records in Austria, Belgium, Germany and the Netherlands with a temporal coverage of at least 58 years and a temporal resolution not coarser than one hour. Our analyses focus on the temporal variability of sub-daily precipitation at multi-decadal to centennial time scales extending earlier work ${ }^{13,22}$. Based on that, we test the hypothesis that the variability found in observed records can be reconstructed using a minimal dynamical downscaling approach based on reanalysis data and a convection parameterization. This approach complements ongoing research on temperature scaling and validating models regarding their capability to reproduce sub-daily precipitation by focusing on downscaling reanalysis data. Therefore, we utilize the Weather Research and Forecasting Model ${ }^{23}$ (WRF) to downscale the Twentieth Century Reanalysis Project dataset ${ }^{24}$ to a spatial and temporal resolution of $30 \mathrm{~km}$ and 10 minutes, respectively. The spatial domain covers Central Europe and the temporal coverage is 1850 - 2014, which allows one to analyse variations from the end of the Little Ice Age (LIA) to near present. Since we apply a coarse regional model which needs a convection parameterization to compute grid cell averages of convective precipitation that are not 
directly comparable to station observations, we compare the observed and modelled variability in subdaily precipitation in terms of anomalies computed as mean of the $95^{\text {th }}, 99^{\text {th }}$, and $99.5^{\text {th }}$ percentiles (Methods).

Anomalies are computed for each station in Figure 1 with overlapping sub-periods of 15 years. Similarly, the same procedure is applied to the downscaled time series derived from the nearest grid point of the model. Figure 2 shows a comparison of these anomalies computed for observed and modelled time series at the Uccle station. Different aggregation levels have been considered in order to highlight variations across process-relevant time scales. The comparison among these temporal resolutions show that the variability of each aggregation level shows a similar course with three maxima, the first in the early $20^{\text {th }}$ century, a second one in the 1960 s and another maximum in the near present. Similarly, minima occur in the 1930s and the 1970s. From the variations achieved for the observational data a slight tendency towards higher variability with decreasing aggregation level is obvious. The downscaled anomalies match the temporal pattern of the observed anomalies very well for this station. However, the differences among aggregation levels are smaller and the overall variability reflects smaller amplitudes.

In the next step, we systematically analysed all stations in a similar way (Supplementary Figure 1) and summarized the comparison for each station and aggregation level in a Taylor diagram ${ }^{25}$ (Figure 3). Here, for reasons of readability, only stations with at least 60 years of data are shown and the full record length is considered for each (the other stations are shown in Supplementary Figure 2). In terms of correlation, the results suggest on average a reasonable to good match of the phase (sequence of minima and maxima in the oscillating temporal course). Pearson correlations range from 0.2 to 0.95 . Except for Oberhausen, sub-daily anomalies show better correlations than daily anomalies. Regarding the variability, the results suggest an underestimation of amplitudes, since the majority of points has a normalized standard deviation smaller than 1. The RMSE ranges from around 0.5 to 1.25 , whereby the majority of runs is characterized by RMSE values smaller than the normalized standard deviation of 1 . For Uccle, we see correlations around 0.7 for $10 \mathrm{~min}$ and $1 \mathrm{~h}$, while the correlation drops to 0.6 
in case of daily data. Similarly, RMSE increases from around 0.7 to 1.0 , also suggesting a drop in model performance. The variability is underestimated for sub-daily data $(<1)$, while daily data matches the variability well (around 1). This observation is in line with the results found in Figure 2. Good results are also found for Duisburg and Soest. The model performance achieved for Andelsbuch near the Alps is also good, at least for sub-daily data. In contrast, the coincidence is generally lower in case of De Bilt and Oberhausen. However, apart from these deficiencies, the minimal dynamical downscaling approach is capable of representing the variability of high precipitation percentiles across Central Europe.

In order to visualize spatial patterns of variations in high precipitation percentiles computed for 10 min aggregation level, Figure 4 compiles a series of maps ranging from the end of the LIA to near present. The maps show that anomalies are heterogeneous in terms of their spatial distribution for each period considered in the maps. Some regions show higher variability (e.g., Northern Germany and Northern Italy), while other regions are subjected to smaller variation (e.g., the regions around the Alps). For instance, the absolute values computed for Andelsbuch are smaller than those computed for the Northern European Plain (including the Netherlands and Northern Germany). The lower part of Figure 4 is a time series of the spatial mean including each map and intermediate steps. The temporal evolution of high precipitation anomalies is in line with those achieved for observed data. From Figure 4 it is obvious that multi-decadal variations found in the observational data (which are mostly in agreement when considering a cross-station comparison) seems to be valid at larger scales as well. Moreover, differences in the amplitudes among different aggregation levels are also visible for large spatial averages suggesting that sub-daily anomalies in high precipitation percentiles are subjected to higher variability in the past 150 years.

The results achieved in the framework of this study highlight that high precipitation percentiles are subjected to multi-decadal oscillations at the centennial scale and that these variations are captured by the minimal downscaling experiment. Moreover, we were able to demonstrate that different aggregation levels of the precipitation time series reflect different magnitudes of variations, 
whereby sub-daily variations are characterized by higher magnitudes than those achieved for daily time series. This outcome is in line with recent findings $s^{4,13}$. In contrast to earlier work we utilized a larger set of long-term station datasets with sub-daily resolution which allows us to more comprehensively validate the minimal downscaling approach based on reanalysis data, which was found to perform reasonably well, albeit its simplicity. Although the validation data is clustered around the Netherlands and Western Germany, the results achieved for Andelsbuch display that the lower variability found for the Alpine region is also captured by the model.

Nevertheless, this study is based on a range of assumptions: (i) First, due to the limitation in terms of data availability, different length of time series is relevant. A direct comparison among all sites is only possible when starting the analyses in 1957. (ii) From a historical overview of measuring sub-daily rainfall ${ }^{26,27}$, it becomes evident that the homogeneity of time series is a source of uncertainty due to changes in instrumentation within long records. Little is known about changes in instrumentations for most sites. For some sites, changes in instrumentation have been reported (e.g., De Bilt ${ }^{28}$ ). We applied the time series 'as is' which means that the analyses might be subjected to uncertainties arising from inhomogeneities relevant for specific characteristics of the time series. (iii) The combination of $30 \mathrm{~km}$ spatial resolution with a small domain and 10 minutes temporal resolution is not a common approach. However, this setup is viewed as a compromise considering computational costs and data storage requirements on the one hand and the focus on variations in rainfall characteristics rather than eventbased considerations on the other. Even though WRF is a proven model that has been tested for various spatial resolutions ${ }^{29,30}$, improved simulations are expected if the model is employed with convection-resolving resolution ${ }^{6,8}$. While Knist et al. ${ }^{30}$ found that the super CC-scaling is not captured well by a non-convection permitting resolution in WRF, the results indicate CC scaling (daily aggregation level) and super-CC-scaling (sub-daily aggregation levels) .

Besides the limitations of the approach demonstrated here, the results are promising to better validate GCMs and RCMs in terms of their capability to simulate long-term variations in sub-daily precipitation. This is especially relevant, since Westra et al. ${ }^{4}$ identified temporal scaling across different 
aggregation levels as one key element relevant for validating RCMs and GCMs in terms of precipitation extremes. This study demonstrates that even a minimal dynamical downscaling approach is capable of reconstructing temporal variation in high precipitation percentiles at the centennial scale. The latter also emphasizes that trend analyses - as usually done for the past three decades only in case of subdaily rainfall - are critical, since both increasing and decreasing trends have been detected similarly throughout the last decades ${ }^{10,12}$ for different spatial and temporal scales. Our results reveal that for some stations a decline in high precipitation percentiles is found and that this decline is also computed by the minimal downscaling approach. This suggests that temporal scaling as key criterion to validate models should also involve the role of climate variability which might obliterate temperatureprecipitation scaling ${ }^{20}$, at least at the decadal scale as it is evident from the time series of anomalies.

A better validation of downscaling approaches regarding their accuracy in sub-daily precipitation modelling is highly relevant for the simulation of future climates with different modelling approaches including GCMs (which still require convection parameterizations) and RCMs with improved spatial resolution and hence an expected increase in the representation of precipitation processes with emphasis on convection. This has also major implications on attribution studies to analyse to what extent anthropogenic forcing contributes to an increase in precipitation extremes.

\section{Methods}

Table 1 provides a summary of the stations involved in our study, while Figure 2 shows a map including the location of each rainfall station. The data was obtained from the data providers listed in Table 1. Except for the most relevant meta data (e.g., coordinates, elevation) little is known about other relevant information relevant for this study like changes in instrumentation or corrections applied to the data. For the Uccle station, a historic overview ${ }^{31}$ and detailed analyses exist ${ }^{13,32}$. The data observed at De Bilt was also subject to numerous analyses relevant to this study ${ }^{14,22}$. The De Bilt dataset available to the authors was corrected by the data provider in order to account for a correction 
been checked carefully which is why we utilize the data in our study 'as is'. The minimum temporal resolution of all time series is at least one hour (Tab. 1). Andelsbuch, Duisburg H. (Hülsermanngraben), Duisburg S. (Schmidthorst), Oberhausen, Soest, and Uccle are stations with sub-hourly time series.

Precipitation intensities with a temporal resolution of $10 \mathrm{~min}$ are computed from the end of the little ice age (LIA) to near present utilizing the Weather Research and Forecasting Model (WRF) ${ }^{23}$ forced by the Twentieth Century Reanalysis Project dataset version 2c (TCRP $)^{24}$ which provides meteorological fields at arbitrary levels every $6 \mathrm{~h}$. The re-analyses dataset acknowledges the fact that radiosonde and remote sensing data were not available in the $19^{\text {th }}$ century, which is why surface and sea level pressure were used as input to the data assimilation. This dataset has been applied in many studies that focus on the climate in past periods especially those considering the end of the LIA or the early $20^{\text {th }}$ century ${ }^{33-}$ 37. The following is a list of parameterizations that have been chosen for the downscaling experiment: Morrison two-moment bulk microphysics ${ }^{38}$; Kain-Fritsch convection scheme ${ }^{39}$, Yonsei University boundary layer scheme ${ }^{40}$; Noah land surface model (LSM) ${ }^{41}$; Dudhia shortwave numerical scheme ${ }^{42}$; and the Rapid Radiative Transfer Model for longwave radiation ${ }^{43}$. WRF was set-up for a domain covering Central Europe, the Alps (to avoid coincidence of the boundary with mountain ranges) and Northern Italy with a single domain covering 64 rows, 44 columns, and 40 vertical levels. This step has been performed using the WRF Pre-processing System (WPS) in order to generate the 6-hourly input files for the period $1851-2014$ based on the TCRP dataset. The corresponding internal time step is 150 seconds. The output is $600 \mathrm{~s}$ corresponding to the target temporal resolution of 10 minutes, which is an integral multiple of the internal time step.

In this study we focus on high precipitation percentiles of $95^{\text {th }}, 99^{\text {th }}$, and $99.5^{\text {th }}$ for which we explore centennial scale variations. These percentiles were also studied by Lenderink et $\mathrm{al}^{22}$. Since the downscaling experiment has a spatial resolution of $30 \mathrm{~km}$, convective events are only considered through a convection parameterization and the precipitation total per time step is an average representative for a grid cell. Thus, a direct comparison of rainfall extremes (e.g., partial or annual series as described by Willems ${ }^{13}$ ) derived for both the observed data and the model is not feasible. 
However, the focus on high percentiles instead of extreme value distributions derived utilizing partial or annual series is beneficial, since rolling averages over extremes along the time axis might introduce oscillations caused by single extreme events ${ }^{44}$ if not considered with special care ${ }^{45}$.

For overlapping periods of 15 years ${ }^{13}$ the average of the $95^{\text {th }}, 99^{\text {th }}$, and $99.5^{\text {th }}$ percentiles $\hat{P}=$ $\overline{\left(P_{95}, P_{99}, P_{99.5}\right)}$ is computed for both the station data and the corresponding grid point in the model. Based on this definition, we compute anomalies for each period of 15 years $n_{\text {sub period }}$ by involving the corresponding average achieved for the entire period (Eq. 1):

$$
n_{\text {sub period }}=\frac{\hat{P}_{\text {sub period }}-\hat{P}_{\text {full period }}}{\hat{P}_{\text {full period }}} \cdot 100 \%
$$

This approach yields an annual series of anomalies in which each year represents an average information of 15 years from seven years before and seven years after the considered year. These anomalies are computed for different aggregation levels ranging from $10 \mathrm{~min}$, to $1 \mathrm{~h}$ and $24 \mathrm{~h}$ representing time scales relevant in different applications in hydrology. For instance, 10 min rainfall is relevant for urban hydrology, torrential flow and flash floods, while hourly values are suitable for studying floods in small catchments. The daily resolution makes the results comparable to many more studies that involve daily rainfall totals only. This temporal scale is also relevant for a lot of applications in hydrology ranging from floods in large river basins to water balance studies. Anomalies computed for observed and modelled time series can be compared using different measures including Pearson correlation. Here, we combine correlation with a comparison of the standard deviation of both time series and the Root Mean Square Error (RMSE) in a Taylor diagram ${ }^{25}$.

\section{Acknowledgements}

This study was only possible thanks to the great support of the data providers. They provided the longterm time series analysed in this study. We wish to thank the following persons and data providers, respectively: Jutta Eybl from the Hydrographic Office at the Ministry of Sustainability and Tourism 
(Austria), Emschergenossenschaft \& Lippeverband (Germany), the Royal Netherlands Meteorological Institute (KNMI), and the Royal Meteorological Institute of Belgium (KMI - IRM).

226

227

\section{Author Contributions}

KF designed the study, compiled the data, and performed the dynamical downscaling experiment. LT further developed the statistical analyses. Both authors discussed the results.

\section{Competing Interest statement}

The authors declare that they have no conflict of interest.

\section{References}

1. Willems, P. Adjustment of extreme rainfall statistics accounting for multidecadal climate oscillations. Journal of Hydrology 490, 126-133 (2013).

2. Mueller, E. N. \& Pfister, A. Increasing occurrence of high-intensity rainstorm events relevant for the generation of soil erosion in a temperate lowland region in Central Europe. Journal of Hydrology 411, 266-278 (2011).

3. Berg, P., Moseley, C. \& Haerter, J. O. Strong increase in convective precipitation in response to higher temperatures. Nature Geosci 6, 181-185 (2013).

4. Westra, S. et al. Future changes to the intensity and frequency of short-duration extreme rainfall. Rev. Geophys. 52, 522-555 (2014).

5. Kendon, E. J. et al. Heavier summer downpours with climate change revealed by weather forecast resolution model. Nature Clim Change 4, 570-576 (2014).

6. Ban, N., Schmidli, J. \& Schär, C. Heavy precipitation in a changing climate: Does short-term summer precipitation increase faster? Geophys. Res. Lett. 42, 1165-1172 (2015). 
7. Fischer, E. M. \& Knutti, R. Observed heavy precipitation increase confirms theory and early models. Nature Clim Change 6, 986-991 (2016).

8. Prein, A. F. et al. The future intensification of hourly precipitation extremes. Nature Clim Change 7, 48-52 (2017).

9. Berg, P. et al. Seasonal characteristics of the relationship between daily precipitation intensity and surface temperature. J. Geophys. Res. 114, D18102 (2009).

10. Łupikasza, E. Seasonal patterns and consistency of extreme precipitation trends in Europe, December 1950 to February 2008. Clim. Res. 72, 217-237 (2017).

11. Tabari, H. \& Willems, P. Lagged influence of Atlantic and Pacific climate patterns on European extreme precipitation. Scientific Reports 8, (2018).

12. Westra, S., Alexander, L. V. \& Zwiers, F. W. Global Increasing Trends in Annual Maximum Daily Precipitation. Journal of Climate 26, 3904-3918 (2013).

13. Willems, P. Multidecadal oscillatory behaviour of rainfall extremes in Europe. Climatic Change 120, 931-944 (2013).

14. Lenderink, G. \& van Meijgaard, E. Increase in hourly precipitation extremes beyond expectations from temperature changes. Nature Geoscience 1, 511-514 (2008).

15. Lenderink, G., Barbero, R., Loriaux, J. M. \& Fowler, H. J. Super-Clausius-Clapeyron Scaling of Extreme Hourly Convective Precipitation and Its Relation to Large-Scale Atmospheric Conditions. J. Climate 30, 6037-6052 (2017).

16. Zhang, X., Zwiers, F. W., Li, G., Wan, H. \& Cannon, A. J. Complexity in estimating past and future extreme short-duration rainfall. Nature Geosci 10, 255-259 (2017).

17. Tripathi, O. P. \& Dominguez, F. Effects of spatial resolution in the simulation of daily and subdaily 
precipitation in the southwestern US. J. Geophys. Res. Atmos. 118, 7591-7605 (2013).

18. Cortés-Hernández, V. E. et al. Evaluating regional climate models for simulating sub-daily rainfall extremes. Clim Dyn 47, 1613-1628 (2016).

19. Gregersen, I. B. et al. Assessing future climatic changes of rainfall extremes at small spatiotemporal scales. Climatic Change 118, 783-797 (2013).

20. Martel, J.-L., Mailhot, A., Brissette, F. \& Caya, D. Role of Natural Climate Variability in the Detection of Anthropogenic Climate Change Signal for Mean and Extreme Precipitation at Local and Regional Scales. Journal of Climate 31, 4241-4263 (2018).

21. Förster, K., Hanzer, F., Winter, B., Marke, T. \& Strasser, U. An open-source MEteoroLOgical observation time series DISaggregation Tool (MELODIST v0.1.1). Geoscientific Model Development 9, 2315-2333 (2016).

22. Lenderink, G., Mok, H. Y., Lee, T. C. \& van Oldenborgh, G. J. Scaling and trends of hourly precipitation extremes in two different climate zones - Hong Kong and the Netherlands. Hydrol. Earth Syst. Sci. 15, 3033-3041 (2011).

23. Skamarock, W. C. et al. A Description of the Advanced Research WRF Version 3. (2008).

24. Compo, G. P. et al. The Twentieth Century Reanalysis Project. Quarterly Journal of the Royal Meteorological Society 137, 1-28 (2011).

25. Taylor, K. E. Summarizing multiple aspects of model performance in a single diagram. J. Geophys. Res. 106, 7183-7192 (2001).

26. Kurtyka, J. C. \& Madow, L. Precipitation measurements study. (Illinois Univ. at Urbana-Chamapaign, 1952).

27. Strangeways, I. A history of rain gauges. Weather $65,133-138$ (2010). 
28. Beersma, J., Bessembinder, J., Brandsma, T., Versteeg, R. \& Hakvoort, H. Actualisatie meteogegevens voor waterbeheer 2015. (2015).

29. Singleton, A. \& Toumi, R. Super-Clausius-Clapeyron scaling of rainfall in a model squall line. Q.J.R. Meteorol. Soc. 139, 334-339 (2013).

30. Knist, S., Goergen, K. \& Simmer, C. Evaluation and projected changes of precipitation statistics in convection-permitting WRF climate simulations over Central Europe. Clim Dyn (2018). doi:10.1007/s00382-018-4147-x

31. Demarée, G. R. Le pluviographe centenaire du plateau d’Uccle: son histoire, ses données et ses applications. La Houille Blanche 4, (2003).

32. De Jongh, I. L. M., Verhoest, N. E. C. \& De Troch, F. P. Analysis Of A 105-year time series of precipitation observed at Uccle, Belgium. International Journal of Climatology 26, 2023-2039 (2006).

33. Michaelis, A. C. \& Lackmann, G. M. Numerical modeling of a historic storm: Simulating the Blizzard of 1888. Geophysical Research Letters 40, 4092-4097 (2013).

34. Xiang-Hui, K. \& Xun-Qiang, B. Dynamical Downscaling of the Twentieth Century Reanalysis for China: Climatic Means during 1981-2010. Atmospheric and Oceanic Science Letters 8, 166-173 (2015).

35. Stucki, P. et al. Evaluation of downscaled wind speeds and parameterised gusts for recent and historical windstorms in Switzerland. Tellus A: Dynamic Meteorology and Oceanography 68, 31820 (2016).

36. Brönnimann, S. Weather Extremes in an Ensemble of Historical Reanalyses. in (Geographica Bernensia, 2017). 
convective system over Liguria: the San Fruttuoso case of 1915. Climate of the Past 13, 455-472 (2017).

38. Morrison, H., Thompson, G. \& Tatarskii, V. Impact of Cloud Microphysics on the Development of Trailing Stratiform Precipitation in a Simulated Squall Line: Comparison of One- and Two-Moment Schemes. Mon. Wea. Rev. 137, 991-1007 (2009).

39. Kain, J. S. The Kain-Fritsch Convective Parameterization: An Update. J. Appl. Meteor. 43, 170-181 (2004).

40. Hong, S.-Y., Noh, Y. \& Dudhia, J. A New Vertical Diffusion Package with an Explicit Treatment of Entrainment Processes. Mon. Wea. Rev. 134, 2318-2341 (2006).

41. Chen, F. \& Dudhia, J. Coupling an Advanced Land Surface-Hydrology Model with the Penn StateNCAR MM5 Modeling System. Part I: Model Implementation and Sensitivity. Monthly Weather Review 569-585 (2001).

42. Dudhia, J. Numerical Study of Convection Observed during the Winter Monsoon Experiment Using a Mesoscale Two-Dimensional Model. J. Atmos. Sci. 46, 3077-3107 (1989).

43. Mlawer, E. J., Taubman, S. J., Brown, P. D., Iacono, M. J. \& Clough, S. A. Radiative transfer for inhomogeneous atmospheres: RRTM, a validated correlated-k model for the longwave. J. Geophys. Res. 102, 16663-16682 (1997).

44. Fischer, S. \& Schumann, A. Comment on the paper of Willems, P.: Multidecadal oscillatory behaviour of rainfall extremes in Europe. Published in: Climatic Change 120 (4), p. 931-944. Climatic Change 130, 77-81 (2015).

45. Willems, P. Author's response to the commentary by S.Fischer \& A.Schumann on 'Multidecadal oscillatory behaviour of rainfall extremes in Europe (Climatic Change, 120(4), 931-944)'. Climatic Change 3 (2015). 


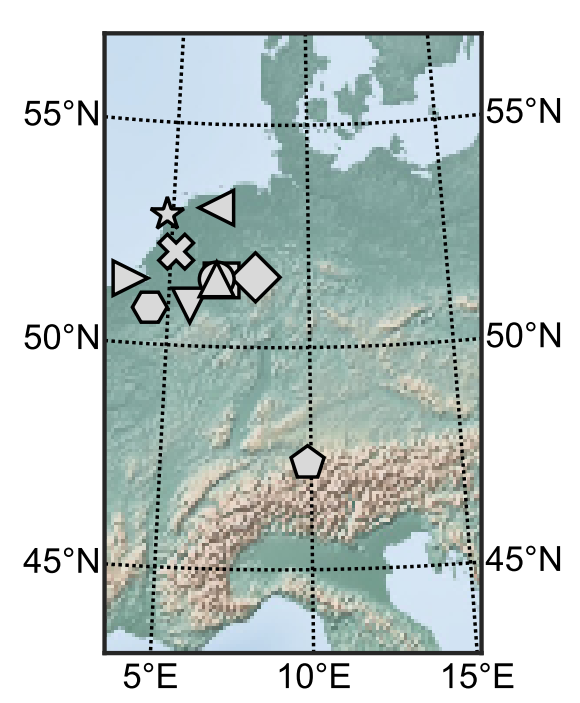

$\triangle$ Andelsbuch (1953)

\ De Bilt (1906)

D De Kooy (1957)

$\bigcirc$ Duisburg-H. (1931)

$\triangle$ Duisburg-S. (1931)

$\triangle$ Eelde (1957)

$\nabla$ Maastricht (1957)

$\square$ Oberhausen (1931)

$\triangle$ Soest (1937)

$\checkmark$ Uccle (1898)

$\triangleright$ Vlissingen (1957)

Figure 1: Map of stations investigated in this study. The number in parentheses indicates the year when recordings began for each station.

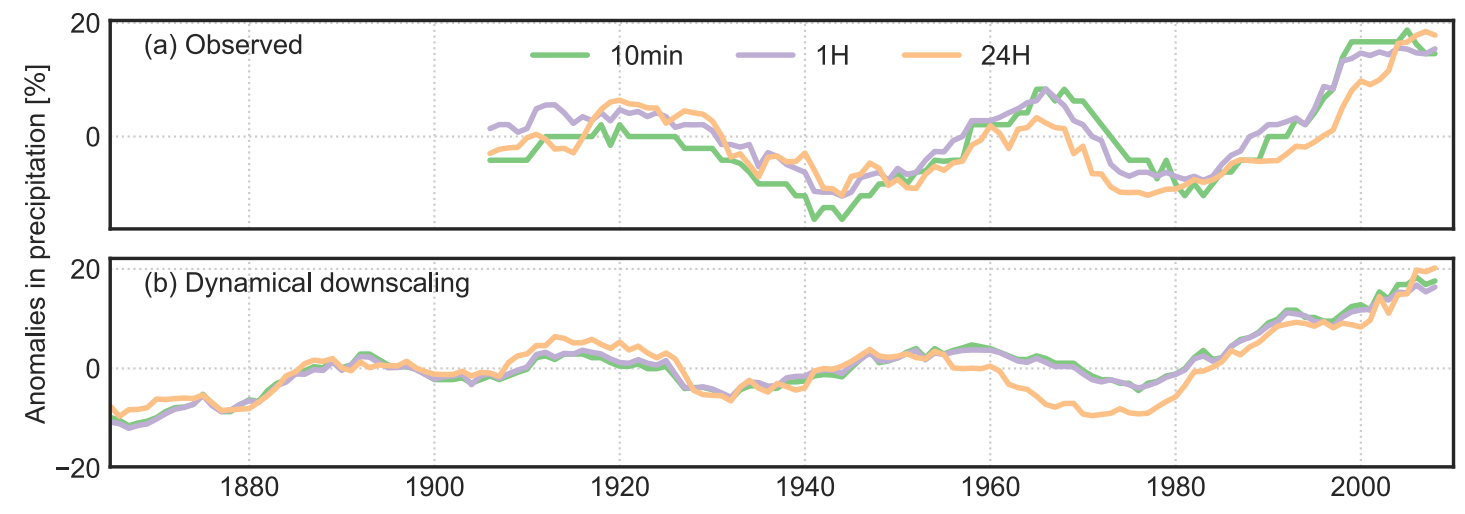

341 Figure 2: Anomalies computed for observed and modelled time series for the Uccle station. The input

342 resolution of $10 \mathrm{~min}$ is also aggregated to $1 \mathrm{~h}$ and $24 \mathrm{~h}$, respectively. (a) observed time series and (b)

343 modelled time series computed utilizing the minimal dynamical downscaling approach. 


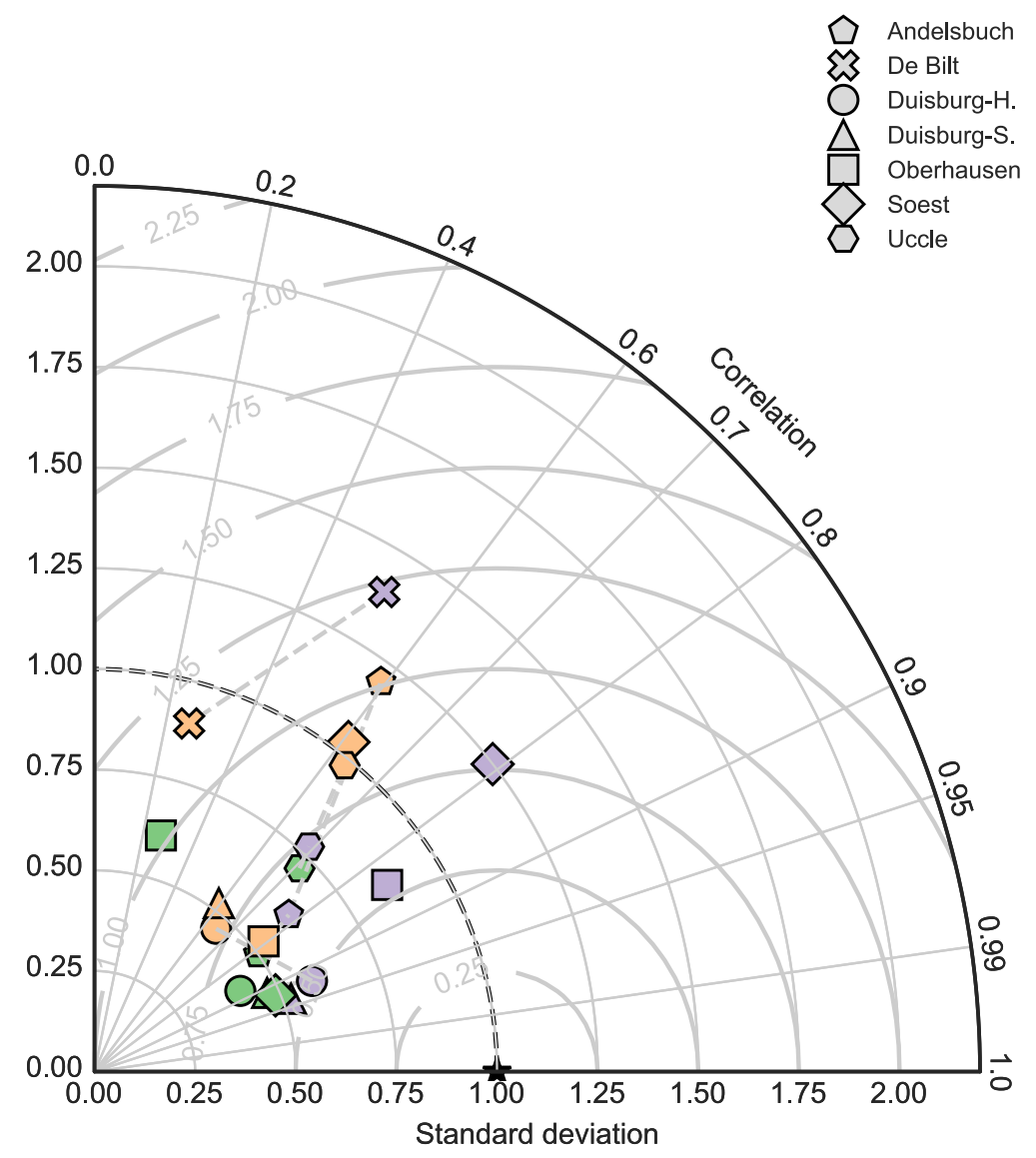

Figure 3: Taylor diagram ${ }^{25}$ including all stations with at least 60 years of data, mostly representing stations with sub-hourly resolution. For each station the full length of the time series is considered. Each comparison is represented by one single point. Aggregation levels are represented by different colours (10 min: green, $1 \mathrm{~h}$ : blue, $24 \mathrm{~h}$ : orange). Ordinate and abscissa refer to the standard deviation of the time series. The radial distance between each point and the origin represents the normalized standard deviation of the model run (corresponding observation is 1 ). The angle between the abscissa and the lines representing the shortest distance of each point to the origin is related to the correlation between observation and model run. The geometric relationship in the Taylor diagram also incorporates the central pattern root mean square error (RMSE) computed for the observation and the model run. The RMSE corresponds to the concentric isolines which are centred around the observation point. The latter has the following characteristics by definition: its standard deviation is 1 , the correlation is 1 and the RMSE is $0 .{ }^{25}$ 

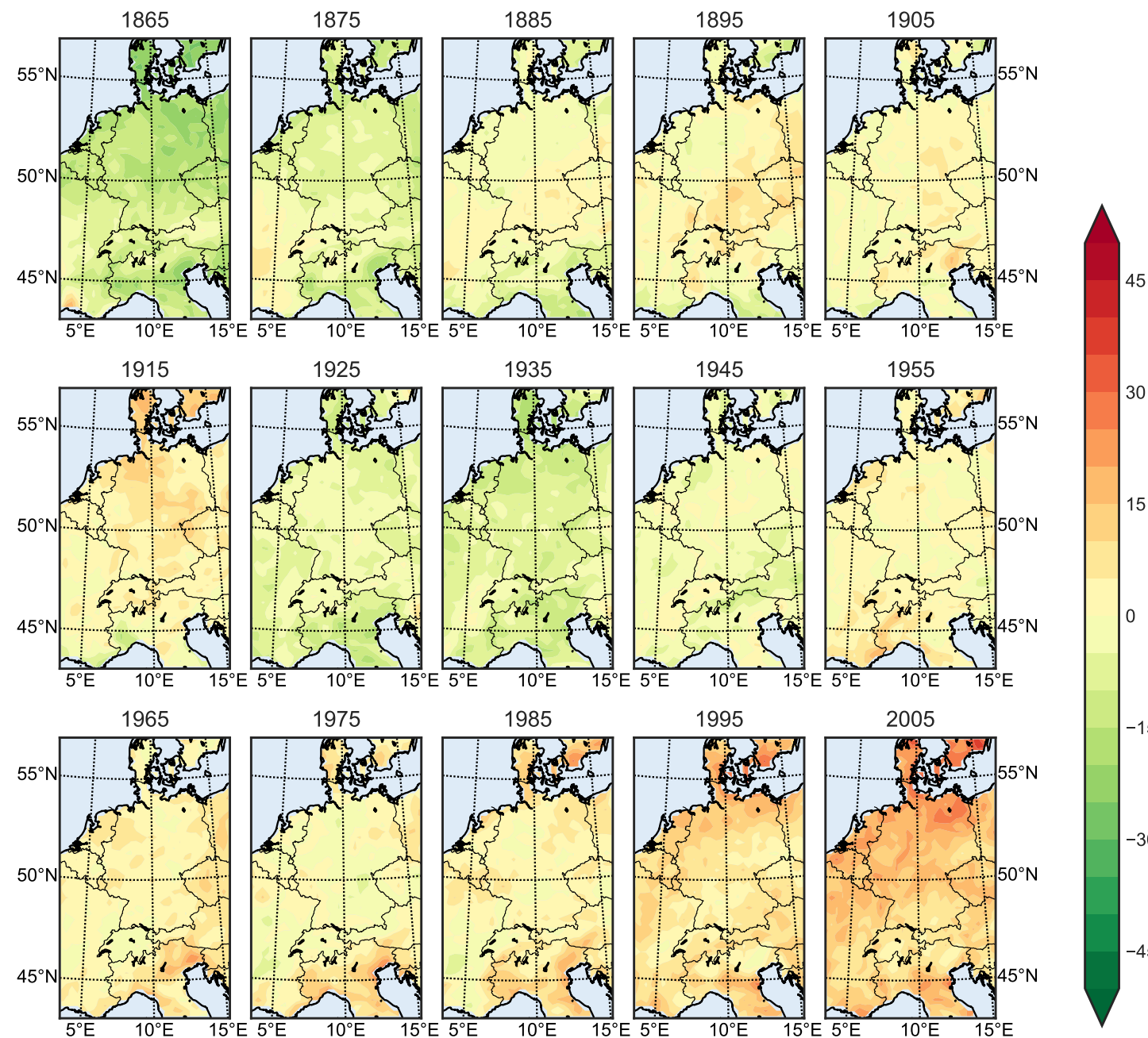

1985

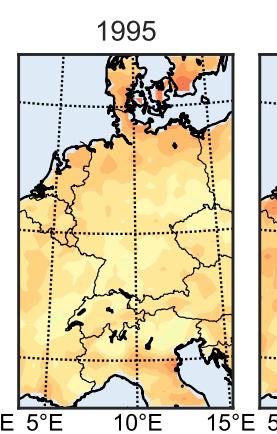

2005
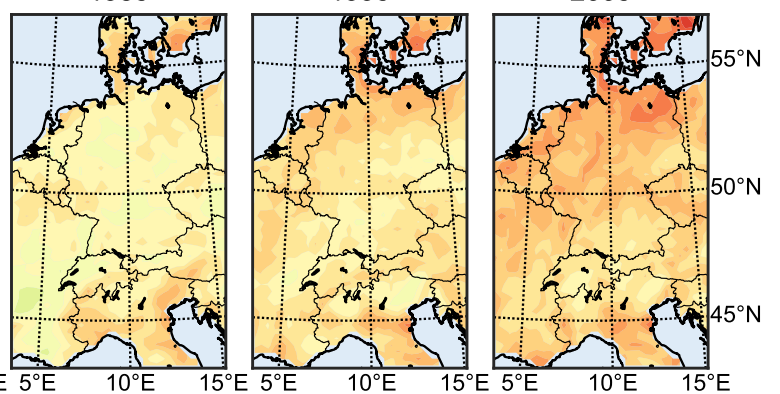

$-15$

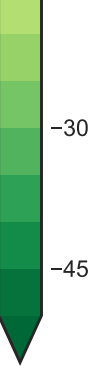

Spatial average time series

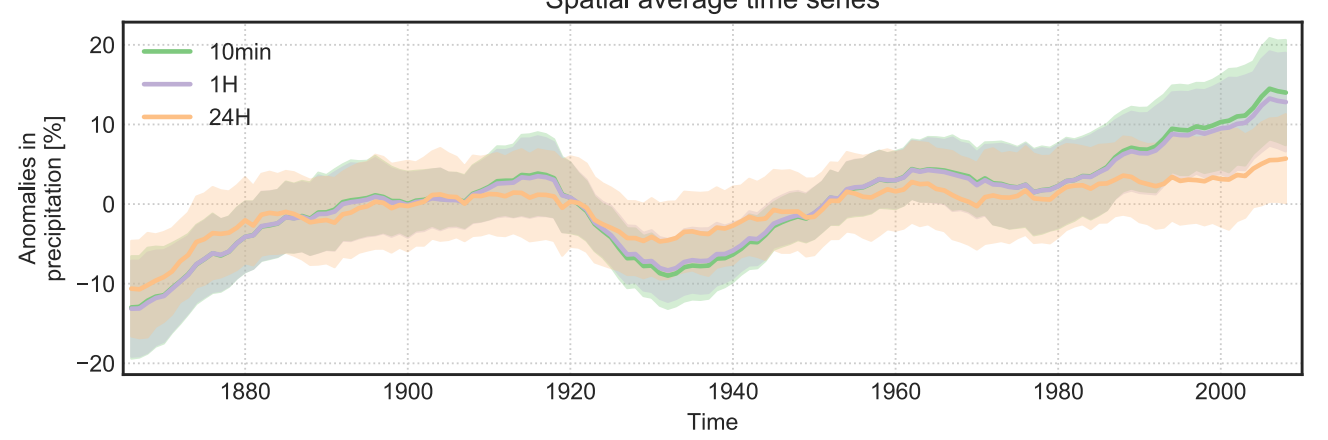

Figure 4: Series of maps showing the spatial distribution of the anomalies in 10 minutes high anomalies are derived through the mean of the $95^{\text {th }}, 99^{\text {th }}$, and $99.5^{\text {th }}$ percentiles computed for moving windows of 15 years, while the reference period is $1850-2014$. In the bottom panel the spatial 


\begin{tabular}{|c|c|c|c|c|}
\hline Station & Country & Data provider & Obs. Started & Resolution \\
\hline Andelsbuch & AT & $\begin{array}{l}\text { Ministry of Sustainability and Tourism / } \\
\text { Hydrographic Office }\end{array}$ & 1953 & $<1 \mathrm{~min}$ \\
\hline De Bilt & NL & $\begin{array}{l}\text { Royal Netherlands Meteorological } \\
\text { Institute (KNMI) }\end{array}$ & 1906 & $1 \mathrm{~h}$ \\
\hline De Kooy & NL & $\begin{array}{l}\text { Royal Netherlands Meteorological } \\
\text { Institute (KNMI) }\end{array}$ & 1957 & $1 \mathrm{~h}$ \\
\hline $\begin{array}{l}\text { Duisburg H. } \\
\text { (Hülsermanngraben) }\end{array}$ & $\mathrm{DE}$ & Emschergenossenschaft \& Lippeverband & 1931 & $1 \mathrm{~min}$ \\
\hline $\begin{array}{l}\text { Duisburg S. } \\
\text { (Schmidthorst) }\end{array}$ & $\mathrm{DE}$ & Emschergenossenschaft \& Lippeverband & 1931 & $1 \mathrm{~min}$ \\
\hline Eelde & NL & $\begin{array}{l}\text { Royal Netherlands Meteorological } \\
\text { Institute (KNMI) }\end{array}$ & 1957 & $1 \mathrm{~h}$ \\
\hline Maastricht & NL & $\begin{array}{l}\text { Royal Netherlands Meteorological } \\
\text { Institute (KNMI) }\end{array}$ & 1957 & $1 \mathrm{~h}$ \\
\hline Oberhausen & $\mathrm{DE}$ & Emschergenossenschaft \& Lippeverband & 1931 & $1 \mathrm{~min}$ \\
\hline Soest & $\mathrm{DE}$ & Emschergenossenschaft \& Lippeverband & 1937 & $1 \mathrm{~min}$ \\
\hline Uccle & $\mathrm{BE}$ & Royal Meteorological Institute of Belgium & 1898 & $10 \mathrm{~min}$ \\
\hline Vlissingen & NL & $\begin{array}{l}\text { Royal Netherlands Meteorological } \\
\text { Institute (KNMI) }\end{array}$ & 1957 & $1 \mathrm{~h}$ \\
\hline
\end{tabular}

average of the domain shown in the maps is displayed as time series plot for different aggregation levels (10 min, $1 \mathrm{~h}$, and $24 \mathrm{~h}$ ). Coloured bands denote \pm one standard deviation. For the last decade (i.e., the 2000s) we found positive anomalies in high precipitation quantiles relative to the reference period $1850-2014$ of $6 \% \pm 5 \%$ (daily), $13 \pm 6 \%$ (hourly), and $14 \% \pm 6 \%$ (10 min). Since 1950, when anomalies were around $0 \%$ for the last time, the mean temperature increased by $1 \mathrm{~K}$ suggesting that the aforementioned positive anomalies are in line with CC-scaling (daily aggregation level) and superCC-scaling (sub-daily aggregation levels), respectively.

Table 1: List of stations involved in the study. The data was obtained from the respective data providers. The column `Obs. Started` indicates when the time series begin and the last column denotes the temporal resolution. 